\title{
Enterochelin acquisition in Campylobacter coli: characterization of components of a binding- protein-dependent transport system
}

\author{
Peter T. Richardson and Simon F. Park
}

Author for correspondence: Simon F. Park. Tel: +44 1734 357227. Fax: +44 1734267917.

Institute of Food Research, Reading Laboratory, Reading, RG6 6BZ, UK

\begin{abstract}
Siderophore-mediated iron uptake systems play a central role in the pathogenesis of infection for many bacterial pathogens. Campylobacter species are not thought to produce siderophores, yet they are able to utilize both ferrichrome and enterochelin as sources of iron. Part of an operon named ceuBCDE, encoding components of a periplasmic binding-protein-dependent transport (PBT) system for the uptake of a ferric siderophore from Campylobacter coli, was cloned directly into Escherichia coli using a plasmid rescue technique. Phenotypic and genetic analyses of this system showed it to comprise two hydrophobic integral membrane proteins, CeuB (35.5 kDa) and CeuC (34.8 kDa), which may form the cytoplasmic membrane permease, an ATP-binding protein, CeuD (28.8 kDa), and a periplasmic substrate-binding protein, CeuE (34.5 $\mathrm{kDa})$. In vivo labelling studies using $\left[{ }^{3} \mathrm{H}\right]$ palmitate demonstrated that CeuE, the periplasmic binding protein, is expressed as a lipoprotein in C. coli, which is unusual for a Gram-negative PBT system. Mutants of $\mathrm{C}$. coli, defective in components of the transport mechanism, were severely impaired in the ability to utilize enterochelin as an iron source suggesting that this siderophore is a substrate for the transport system. This is the first molecular characterization of a PBT system in Campylobacter species.
\end{abstract}

Keywords: Campylobacter coli, enterochelin, lipoprotein, siderophore, ceu

\section{INTRODUCTION}

Campylobacter coli and Campylobacter jejuni are now recognized to be one of the major causes of bacterial gastroenteritis in the developed world (Tauxe, 1992). In addition, these pathogenic bacteria are also carried as commensals in a wide variety of animals which may form reservoirs for the human disease (Griffiths \& Park, 1990). Despite the epidemiological significance of this group of organisms the pathophysiology of infection in this group of bacteria is poorly understood (Walker et al., 1986). This is partly due to lack of characterization of the genetic elements important to virulence and inadequate animal models to test potential virulence determinant mutants.

Iron is essential for the growth of most bacteria but has very low solubility under physiological conditions. Furthermore, in humans the availability of iron for microbial

Abbreviations: EDDHA, ethylenediamine-di-o-hydroxyphenylacetic acid; PBT, periplasmic binding-protein-dependent transport.

The GenBank accession number for the nucleotide sequence data reported in this paper is $X 88849$. assimilation is limited because of its sequestration by high-affinity iron-binding proteins such as transferrin and lactoferrin which occur in serum and at mucosal surfaces (Weinberg, 1984). The ability to acquire this essential element under iron-limited conditions present within the host, therefore, is considered to be critical to the virulence and survival of a number of bacterial pathogens (Payne \& Lawlor, 1990). As a response to this nutritional restriction bacteria have evolved highly efficient systems for sequestering iron (Briat, 1992; Wooldridge \& Williams, 1993). A strategy for iron sequestration employed by many micro-organisms comprises the secretion of highly specific chelators for ferric ions, termed siderophores (Neilands, 1981; Braun \& Hantke, 1991), followed by their re-internalization via a cognate high-affinity transport system and the subsequent release of iron into the cytoplasm (Crosa, 1989; Braun \& Hantke, 1991).

Successful colonization of the gastrointestinal tract requires effective mechanisms for acquiring iron in this complex nutritional milieu. Campylobacter spp. do not, however, appear to produce detectable levels of siderophores (Baig et al., 1986). It is likely, therefore, that these 
bacteria can compete successfully in the heterogeneous competitive environment of the gastrointestinal tract by scavenging siderophores produced by the indigenous microflora. For instance, strains of both $C$. coli and $C$. $j e j u n i$ are able to acquire iron from enterochelin (Baig et al., 1986; Field et al., 1986), the phenolate-type siderophore produced by Eschericbia coli and other enteric bacteria (Neilands, 1981). The transport of siderophores in other Gram-negative bacteria is well characterized yet very little is known about the transport systems for their uptake in Campylobacter spp. Gram-negative bacteria have two membranes, an outer one and an inner one, hence transport of siderophores must occur in two steps. Firstly, the complex is transported across the outer membrane into the periplasm via a specific receptor. Transport of siderophores across the cytoplasmic membrane then occurs via a periplasmic binding-protein-dependent (PBT) system (Braun \& Hantke, 1991). All known PBT systems consist of a periplasmic component, one or two hydrophobic components embedded within the cytoplasmic membrane, and a peripheral cytoplasmic component most likely involved in energy coupling (Ames $e t$ al., 1990; Higgins, 1992). Analogous systems exist in Gram-positive bacteria (Alloing et al., 1990; Schneider \& Hantke, 1993) but, in the absence of an outer membrane, there is no requirement for outer-membrane receptors. Instead, the binding-protein component is lipophilically modified and this is thought to facilitate its anchorage to the cytoplasmic membrane preventing its escape into the extracellular environment (Gilson et al., 1988).

In a previous study, we identified a lipophilically modified protein from C. jejuni which showed significant homology to periplasmic siderophore-binding proteins (Park \& Richardson, 1995). Here we identify its homologue in $C$. coli and, by characterizing genes upstream of the siderophore-binding protein, demonstrate that it is a component of a binding-lipoprotein-dependent transport system for enterochelin uptake. This is the first molecular characterization of a PBT system for any Campylobacter species.

\section{METHODS}

Bacterial strains and culture. The strains and plasmids used in this study are listed in Table 1. Campylobacter cultures were routinely grown at $37^{\circ} \mathrm{C}$ on Mueller-Hinton ( $\mathrm{MH}$ ) agar under microaerophilic conditions using the recommended gas generating kit (Oxoid). E. coli JM101, used during plasmid construction, was grown aerobically in LB-broth or on LB-agar (Gibco BRL). For testing the ability of strains of $C$. coli to utilize haemin and enterochelin, bacteria were seeded in $\mathrm{MH}$-agar containing $56 \mu \mathrm{M}$ ethylenediamine-di-o-hydroxyphenylacetic acid (EDDHA; Sigma) which had been deferrated by the procedure of Rogers (1973). Filter paper discs impregnated with $10 \mu \mathrm{l}$ of $100 \mu \mathrm{M}$ or $1 \mathrm{mM}$ concentrations of either haemin (Sigma) or enterochelin (kindly provided by J. B. Neilands, University of California) were placed upon the agar and the plates incubated for $24 \mathrm{~h}$ to assess the growth stimulation. When necessary, the antibiotics ampicillin and tetracycline were used at concentrations of $100 \mu \mathrm{g} \mathrm{ml}^{-1}$ and $10 \mu \mathrm{g} \mathrm{ml}^{-1}$, respectively.

Cloning of the ceuBCDE operon by plasmid rescue. A DNA fragment containing part of the $c e u E$ gene of $C$. coli UA585 was generated using PCR. A commercial Taq DNA polymerase system (Perkin Elmer Cetus) was used to amplify target DNA (C. coli UA585 chromosomal DNA) in the presence of deoxynucleotides $(50 \mu \mathrm{M})$. A total of 26 cycles was used, each including a $30 \mathrm{~s}$ denaturation step at $94^{\circ} \mathrm{C}$, a $30 \mathrm{~s}$ annealing step at $45^{\circ} \mathrm{C}$, followed by a $2 \mathrm{~min}$ extension step at $72^{\circ} \mathrm{C}$. The primers with homology to $c e u E$ had the sequence: $5^{\prime}$ CAGCTTGCGATTCTAAATCCA $3^{\prime}$ and $5^{\prime}$ TCTCTTGTTGAAGAGAATGT 3'. A 513 bp Sau3A fragment, internal to the fragment generated by PCR, was then cloned into the BamHI site of the integrational plasmid pSP105 (Dickinson $e t$ al., 1995) and the resulting plasmid was designated pSP120. This plasmid was introduced into $C$. coli UA585 by natural transformation (Wang \& Taylor, 1990). The chromosomal DNA from one tetracycline-resistant transformant, designated $\mathrm{CCH} 1$, was analysed by Southern hybridization and the $c e u E$ gene was shown to contain a single integrated copy of pSP120. Chromosomal DNA was isolated from this strain using the method of Pitcher et al. (1989) and the DNA digested with either SacI or Pst I to excise the integrated plasmid and flanking DNA. The restricted DNA was diluted to $20 \mathrm{ng} \mathrm{\mu l}^{-1}$, then ligated and used to transform E. coli to ampicillin resistance. The plasmids pS1 and $\mathrm{pP} 1$, generated using this procedure, are described in Table 1. The same technique was used to excise the plasmid pS2 (Table 1) from the chromosome of CATP1 using the restriction enzyme SphI.

Recombinant DNA techniques. Standard techniques including plasmid mini preparations, restriction endonuclease digestions, ligations and transformation into $E$. coli were according to standard procedures (Maniatis et al., 1982). Large-scale plasmid preparations were prepared using affinity columns according to the manufacturer's instructions (Qiagen). Double-stranded DNA sequencing was performed using standard methods (Sanger et al., 1977) with [ $\left.{ }^{35} \mathrm{~S}\right] \mathrm{dATP} \alpha \mathrm{S}$ and using a Sequenase version 2.0 kit (United States Biochemical). The insert in pS1 was sequenced in its entirety using primers designed to bind to opposing strands at approximately $200 \mathrm{bp}$ intervals allowing sequence data to be obtained independently from both strands. Regions of the nucleotide sequences in the inserts of $\mathrm{pP} 1$ and $\mathrm{pS} 2$ were determined in the same manner. Oligonucleotides were synthesized using a 391 DNA synthesizer (Applied Biosystems). Computer analysis of the sequence data was carried out using the University of Wisconsin molecular biology software package (Devereux et al., 1984).

Analysis of plasmid-encoded proteins. The polypeptides encoded by $\mathrm{pS} 1$ were identified using an E. coli in vitro coupled transcription/translation system (Promega). Proteins were radiolabelled by incubation with $20 \mu \mathrm{Ci} \quad(740 \mathrm{kBq})$ $\left.{ }^{35} \mathrm{~S}\right]$ methionine (Amersham). Polypeptides were separated on $10 \%$ (w/v) SDS-polyacrylamide gels (Laemmli, 1970) using Rainbow ${ }^{14} \mathrm{C}$-methylated markers (Amersham) as molecular size standards. Radiolabelled bands were visualized by fluorography at $-70^{\circ} \mathrm{C}$.

In vivo labelling of iron-repressible lipoproteins with $\left[{ }^{3}\right.$ H]palmitate. Lipoproteins were labelled specifically using $\left[{ }^{3} \mathrm{H}\right]$ palmitate. Cells of $\mathrm{C}$. coli UA585 and $\mathrm{CCH} 1$ were grown in $\mathrm{MH}$-broth to exponential phase, and iron-repressible protein expression was then induced by the addition of $20 \mu \mathrm{M}$ deferrated EDDHA which restricted the availability of iron. At this point $20 \mu \mathrm{Ci}(740 \mathrm{kBq})\left[9,10(\mathrm{n}){ }^{3} \mathrm{H}\right]$ palmitate $\mathrm{ml}^{-1}$ (Amersham) was added and the incubation continued at $37^{\circ} \mathrm{C}$ for $6 \mathrm{~h}$. Cells were harvested and washed twice in methanol to remove unincorporated radioactive precursors and non-covalently bound lipids. The dried cell pellets were then boiled in SDS-loading buffer and analysed using SDS-PAGE gels as described 
Table 1. Bacterial strains and plasmids

\begin{tabular}{|c|c|c|}
\hline Strain/plasmid & Genotype/relevant characteristics & Source/reference \\
\hline \multicolumn{3}{|l|}{ E. coli } \\
\hline JM101 & $\begin{array}{l}\mathrm{F}^{\prime} \operatorname{traD} 36 \text { lac }^{\mathrm{a}} \Delta(\text { lac } Z) \mathrm{M} 15 \text { pro } A B / \sup E \\
\text { thi } \Delta(\text { lac-pro } A B)\end{array}$ & Yanisch-Perron et al. (1985) \\
\hline \multicolumn{3}{|l|}{ C. coli } \\
\hline UA585 & Parental strain & Wang \& Taylor (1990) \\
\hline $\mathrm{CCH} 1$ & ceuE::pSP120 & Current study \\
\hline CATP1 & $c e u D:: \operatorname{pSP} 180$ & Current study \\
\hline CFED1 & $\Delta(c e u B-c e u D)$ & Current study \\
\hline \multicolumn{3}{|l|}{ Plasmids } \\
\hline pSP105 & Campylobacter integrative plasmid, Tet $^{\mathbf{R}}$ & Dickinson et al. (1995) \\
\hline pSP120 & $\begin{array}{l}513 \text { bp Sau3A fragment, internal to } c e u E \text {, } \\
\text { cloned into pSP105 }\end{array}$ & Current study \\
\hline pSP180 & $\begin{array}{l}370 \text { bp } B g / \mathrm{II} / E c o \mathrm{RV} \text { fragment, internal to } \\
c e u D \text {, cloned into pSP105 }\end{array}$ & Current study \\
\hline pS1 & $\begin{array}{l}\text { Plasmid excised from CCH1 with } S_{a c I} \\
\text { contains } 3 \cdot 2 \mathrm{~kb} \text { of DNA upstream of } \\
\text { ceuE }\end{array}$ & Current study \\
\hline pS2 & $\begin{array}{l}\text { Plasmid excised from CATP1 using } S_{p b I}, \\
\text { contains } 24 \mathrm{~kb} \text { of DNA upstream of } c e u D\end{array}$ & Current study \\
\hline $\mathrm{pP} 1$ & $\begin{array}{l}\text { Plasmid excised from } \mathrm{CCH}^{2} \text { using } P_{s t} \mathrm{I} \\
\text { contains } 10 \mathrm{~kb} \text { of DNA downstream of } \\
\text { ceuE }\end{array}$ & Current study \\
\hline pCFF1 & $\begin{array}{l}\text { pTZ19R with a } 2 \cdot 1 \mathrm{~kb} \text { SacI/EcoRV insert } \\
\text { containing ceuC }\end{array}$ & Current study \\
\hline pCFED1 & $\begin{array}{l}\text { pCFF1 in which } 1.47 \mathrm{~kb} \text { of DNA internal } \\
\text { to the insert was replaced by a } \text { Tet }^{\mathrm{R}} \\
\text { marker }\end{array}$ & Current study \\
\hline pTZ19R & General cloning vector & Mead et al. (1986) \\
\hline
\end{tabular}

previously (Laemmli, 1970). Radiolabelled bands were visualized by fluorography at $-70^{\circ} \mathrm{C}$.

DNA/DNA hybridizations. DNA/DNA hybridizations were carried out using a non-radioactive ECL gene detection kit (Amersham). Chromosomal DNA from various strains of $C$. coli UA585 and CFED1 was restricted using $B g / \mathrm{II}$ and electrophoresed on a $0.8 \%$ agarose gel. Gel-electrophoresed DNA was depurinated by gently shaking the gel in $250 \mathrm{mM} \mathrm{HCl}$ for $30-45 \mathrm{~min}$ and the DNA transferred to Hybond $\mathrm{N}+$ nitrocellulose membranes (Amersham) using an alkali transfer procedure (Maniatis et al., 1982). The DNA insert in pCFF1 or the $1.30 \mathrm{~kb} \mathrm{Bg} / \mathrm{II}$ fragment internal to this was labelled and used as a DNA probe to detect cross-hybridizing species, following the manufacturer's guidelines.

\section{RESULTS}

\section{Cloning of the enterochelin-uptake system from $C$. coli by plasmid rescue}

An earlier study from this laboratory reported the characterization of lipoprotein from $C$. jejuni which has significant homology to siderophore-binding proteins (Park \& Richardson, 1995). A 957 bp DNA fragment, containing part of the gene encoding the equivalent protein in C. coli, was isolated using PCR. Subsequently, a 513 bp Sau3A fragment, internal to the gene (Fig. 1), was subcloned into the Bam HI site of the Campylobacter integrational vector pSP105 (Dickinson et al., 1995) to generate the plasmid pSP120. To clone the regions flanking the gene encoding the putative siderophorebinding protein a plasmid rescue method was used. The plasmid pSP120 was introduced into $C$. coli UA585 by natural transformation (Wang \& Taylor, 1990) and tetracycline-resistant transformants were recovered. As the plasmid is not capable of extrachromosomal replication the only way for this antibiotic-resistant phenotype to arise is if the plasmid becomes integrated into the chromosome by a single point crossover driven by homologous recombination at the region of homology. One transformant, designated $\mathrm{CCH} 1$, was shown by Southern hybridization to contain such an integrated element (data not shown). The integrated derivative of pSP120 present in the chromosome of $\mathrm{CCH} 1$ contains an intact copy of the plasmid flanked by genomic DNA and, accordingly, will contain a colE replicon and antibioticresistance markers which are expressed in E. coli. Plasmid DNA containing the sequences flanking the site of integration is generated following ligation of chromosomal DNA which has been digested with any restriction enzyme that has a unique site within the multilinker of pSP120. Digestion of chromosomal DNA from CCH1 with the enzymes $S_{a c} \mathrm{I}$ or $P s t \mathrm{I}$ released integrated plasmids including $3 \cdot 2 \mathrm{~kb}$ of flanking upstream DNA and $10 \mathrm{~kb}$ of 


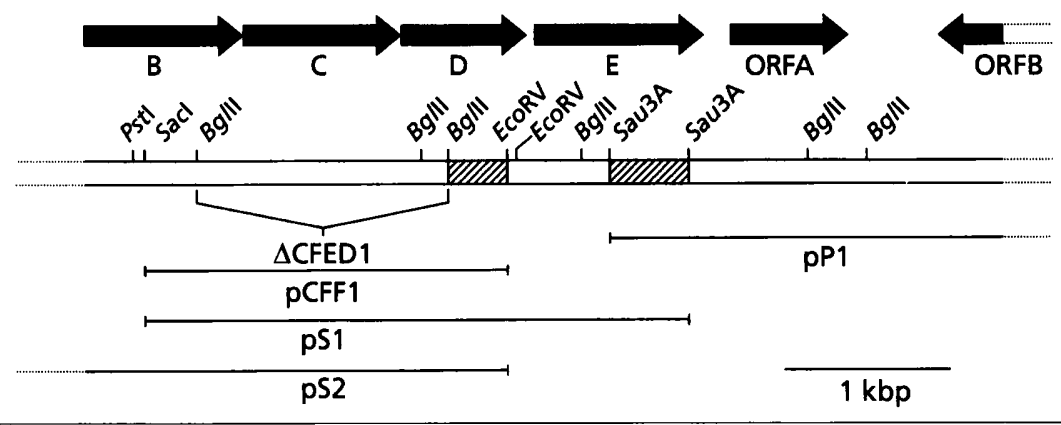

Fig. 1. Partial restriction map of the $C$. coli chromosomal region containing the ceu loci. The 513 bp Sau3A fragment and the 370 bp $B g / l l / E$ coRV fragment cloned into the integrative vectors PSP120 and PSP180 are indicated by the hatched areas. Inserts contained in the plasmids, which were excised by plasmid rescue, and derivatives, are indicated by single lines beneath the restriction map. The extent of the deletion present in $C$. coli CFED1 is denoted by $\triangle$ CFED1.

flanking downstream DNA (Fig. 1) which were designated $\mathrm{pS} 1$ and $\mathrm{pP} 1$, respectively. The plasmid $\mathrm{pS} 2$, which contains $24 \mathrm{~kb}$ of DNA upstream of the site of integration DNA, was generated in a similar fashion but was excised from CATP1 (Table 1) using $S p h I$.

\section{Sequence analysis and protein expression studies of the enterochelin-uptake operon}

To establish whether the gene encoding the lipoprotein with homology to siderophore-binding proteins was part of an operon encoding a PBT system, the nucleotide sequences of the insert in $\mathrm{pS} 1$ and parts of inserts in pP1 and pS2 were determined. The operon subsequently characterized in the following pages was designated ceu (Campylobacter enterochelin uptake). The plasmid pS1 carried a $3.2 \mathrm{~kb}$ insert containing the $5^{\prime}$ end of the $c e u E$ gene (Fig. 1), encoding the lipoprotein with homology to siderophore-binding proteins. In addition, two complete ORFs, designated ceuD and ceuC, and the $3^{\prime}$ end of an ORF termed $c e u B$ were apparent in the insert (Figs 1 and 2 ). The nucleotide sequence of the $5^{\prime}$ end of $c e u B$ was determined from pS2 since this plasmid contained $C$. coli chromosomal DNA which was originally upstream of the SacI site at which $\mathrm{pS} 1$ was excised from the chromosome (Fig. 1). Sequence analysis of part of the insert in pP1, which was proximal to the site of the integration of pSP120, showed it to contain the $3^{\prime}$ end of ceuE. An unidentified ORF, designated ORFA, and an incomplete ORF (ORFB), which was orientated in the opposite direction, were apparent in the DNA which was downstream of $c e u E$ (Figs 1 and 2).

The ORF for ceuB, which most likely starts at position 24 and is preceded by a well-defined Shine-Dalgarno sequence (Fig. 2), potentially encodes a protein of 322 amino acids with a calculated molecular mass of $35.5 \mathrm{kDa}$. The first codon of the next gene, $c e u C$, at position 985 occurs within the reading frame of $c e u B$, indicating that these proteins are translationally coupled. The start codon is preceded by a well-conserved Shine-Dalgarno sequence. ceuC encodes a protein of 311 amino acids, the calculated molecular mass of which is $34.8 \mathrm{kDa}$. This is in good agreement with a protein which was expressed from $\mathrm{pS} 1$, using an in vitro coupled transcription/translation system, with an observed mass of $34 \mathrm{kDa}$ (Fig. 3). The termination codon of $c e u C$ and the start of the next gene, $c e u D$, at position 1920 overlap, suggesting that these two genes are also translationally coupled. In this case, the start codon again appears to be preceded by a well-defined Shine-Dalgarno sequence. The putative CeuD protein of 251 amino acids has a calculated mass of $28.8 \mathrm{kDa}$, which is consistent with a protein, migrating with an apparent molecular mass of $28 \mathrm{kDa}$, which is expressed in vitro from pS1 (Fig. 3). Thirteen bases separate the termination codon of ceuD and the start codon of the next gene, ceuE, at position 2689 (Fig. 2), which is preceded by a wellconserved Shine-Dalgarno sequence. ceuE encodes a protein of 328 amino acids, the first 21 amino acids of which have the characteristics of a typical lipoprotein signal sequence, with the signal peptidase II consensus recognition sequence ${ }^{18} \mathrm{~L}-\mathrm{T}-\mathrm{A}-{ }^{21} \mathrm{C}$ (von Heijne, 1989; Pugsley, 1993). The mature protein with 308 amino acids $(33.7 \mathrm{kDa})$ and with lipid modification (approximately $789 \mathrm{Da})$ would have an expected molecular mass of $34.5 \mathrm{kDa}$. The homologous gene from $C$. jejuni, which contains an identical signal sequence, was expressed as a $33.8 \mathrm{kDa}$ lipoprotein in E. coli (Park \& Richardson, 1995). The plasmid pS1 carries the $5^{\prime}$ end of the $c e u E$ gene extending to the Sau3A site at position 3589 (Figs 1 and 2), with the potential to encode a polypeptide of 300 amino acids. The immature version of this protein would have an expected molecular mass of $32.9 \mathrm{kDa}$. No protein of this size was apparent when $\mathrm{pS} 1$ was used as a template in an in vitro coupled transcription/translation system. Instead, two proteins of $26.0 \mathrm{kDa}$ and $27.0 \mathrm{kDa}$ were expressed uniquely from $\mathrm{pS} 1$, and not the parental plasmid pSP105 (Fig. 3). Since these are unlikely to originate from the other characterized ORFs in pS1 they may represent degradation products of the truncated CeuE protein. An intergenic region of $166 \mathrm{bp}$ separates the termination codon of ceuE from the start codon of the next ORF, designated ORFA. As this region contains a inverted repeat capable of forming a stem-loop structure, typical of a rho-independent terminator, it is likely that $c e u E$ represents the last gene in the ceu operon and that ORFA is transcribed independently. ORFA has the potential to encode a protein of 210 amino acids with a calculated molecular mass of $22.8 \mathrm{kDa}$. A search of the GenBank database using the amino acid sequence of the putative polypeptide revealed no significant homologies to any previously characterized protein. In addition, the $3^{\prime}$ end of another ORF, designated ORFB was apparent $670 \mathrm{bp}$ downstream of the termination codon of ORFA. Since this ORF is orientated in the opposite direction compared to that of ORFA and the ceu operon, it is likely that this gene is transcribed independently of either of these. 


\section{Inactivation of the ceuB, ceuC, ceuD and ceuE genes}

Sequence analysis of the region upstream of ceuE suggested that the genes may form an operon encoding a PBT system for a ferric siderophore. To confirm this hypothesis and to determine the identity of the substrate(s) which were transported by this uptake system, genes encoding chosen components of the system were inactivated by mutation. The integration of plasmid pSP120 into the ceuE gene of $C$. coli $\mathrm{CCH} 1$ initially provided a means of cloning the DNA flanking this gene directly into $E$. coli by plasmid rescue. However, because the insert containing the region of homology in pSP120 was internal to the ceuE gene then the integrative event will also have generated a disrupted copy of ceuE (Dickinson et al., 1995). Campylobacter spp. have been shown to be able to use both haemin and the siderophore enterochelin as sources of iron (Baig et al., 1986; Field $e t$ al., 1986; Pickett et al., 1992). The capacity of the ceuE mutant $\mathrm{CCH} 1$ to utilize either of these iron sources was, therefore, assessed. Cells were added to $\mathrm{MH}$-agar plates containing EDDHA, which binds iron to make it unavailable to $C$. coli (Field et al., 1986). Growth can only occur, therefore, when exogenous iron sources are supplied and if the bacteria are able to utilize these. The stimulation of growth due to $1 \mathrm{mM}$ and $100 \mu \mathrm{M}$ haemin was equivalent for both mutant and wild-type cells, suggesting that ceuE mutation did not affect haemin uptake. In contrast, however, when enterochelin was supplied as an iron source at a concentration of $1 \mathrm{mM}$ the zone of growth of the mutant strain was both smaller and less dense when compared to that observed for the parental strain (Table 2). When lower concentrations of enterochelin were available $(100 \mu \mathrm{M})$, a very poor growth response was observed for $\mathrm{CCH} 1$ although a good growth stimulation was apparent for wild-type cells. The same mechanism of mutation by single site integration of plasmid DNA was utilized to disrupt the $c e u D$ gene. To facilitate this, a $0.37 \mathrm{~kb} B g / \mathrm{l} /$ EcoRV fragment, internal to ceuD (Fig. 1), was cloned into pSP105 (Dickinson et al., 1995). The resulting integrative plasmid, pSP180, was introduced into $C$. coli UA585 by natural transformation and the nature of the mutagenic integrative event in one transformant, designated $C$. coli CATP1, was confirmed by Southern hybridization (data not shown). When the capacity of CATP1 to utilize enterochelin as an iron source was assessed, no growth response was apparent when the siderophore was supplied at a concentration of $100 \mu \mathrm{M}$. A very weak zone of stimulation was observed when enterochelin was present at $1 \mathrm{mM}$. In contrast, the ability of $C$. coli to utilize haemin as an iron source was unaffected by the presence of the ceuD mutation (Table 2).

Allelic exchange has been utilized previously in Campylobacter species to generate mutation by introducing copies of genes disrupted by antibiotic markers into the chromosome (Labigne-Roussel et al., 1988). In order to determine the role of the inner-membrane permease complex in the uptake of enterochelin, we decided to disrupt the expression of these components by generating a $c e u B-c e u D$ deletion mutant by allelic exchange. To facilitate this, a $2 \cdot 1 \mathrm{~kb} S a c \mathrm{I} /$ EcoRV fragment (Fig. 1) was cloned into pTZ19R (Mead et al., 1986) and the resulting plasmid was designated pCFF1. The DNA between the two $B g / I I$ sites at positions 659 and 2132 (Fig. 2), encompassing ceuC, the $3^{\prime}$ end of ceuB and the $5^{\prime}$ end of $\operatorname{ceuD}$ (Fig. 1), was then removed and replaced by a $B g / \mathrm{II}$ tetracycline-resistance cassette (Dickinson et al., 1995) to generate pCFED1. The disrupted sequence was isolated from pCFED1 as a BamHI/Pst I cassette and then introduced into $C$. coli via natural transformation, and tetracycline-resistant transformants were recovered. To confirm the introduction of the deleted sequence element into the chromosome, total DNA from one transformant designated CFED1 was analysed by Southern hybridization (Fig. 4). When DNA isolated from the wildtype was probed with the entire insert in PCFED1 four bands of $5.00 \mathrm{~kb}, 1.30 \mathrm{~kb}, 0.78 \mathrm{~kb}$ and $0.16 \mathrm{~kb}$ showed homology to the probe. This pattern is predictable, given the arrangement of $B g l I I$ sites in the cloned DNA (Fig. 1). In DNA from the CFED1, however, the $5.00 \mathrm{~kb}$ and $0.78 \mathrm{~kb}$ bands were still apparent, but the $1.30 \mathrm{~kb}$ and $0.16 \mathrm{~kb}$ bands were absent, demonstrating that the DNA between the $B g / I I$ sites at positions 659 and 2131 (Figs 1 and 2) is absent from CFED1. To confirm this the $1.30 \mathrm{~kb}$ $\mathrm{Bg} / \mathrm{II}$ fragment, removed during the construction of pCFED1, was used to probe DNA derived from the mutant and parental strains. In this case the probe hybridized to the $1.30 \mathrm{~kb}$ fragment in the DNA from the parent but not to DNA from the mutant. The Southern hybridization data confirm the absence of the chromosomal DNA encoding ceuC, the $3^{\prime}$ end of $c e u B$ and the $5^{\prime}$ end of $c e u D$ in the deletion mutant CFED1 and also demonstrate that the gene replacement had been very precise since the $B g / \mathrm{II}$ sites and the DNA flanking the deletion remain unaltered. Phenotypic studies of CFED1 showed it to be deficient in the utilization of enterochelin as an iron source and it exhibited the same growth response to the siderophore as CATP1 (Table 2).

\section{ceuE encodes a putative enterochelin-binding lipoprotein}

The amino acid sequences of CeuE from both $C$. coli and C. jejuni show significant homology to the periplasmic siderophore-binding proteins from other bacterial iron acquisition systems. Furthermore, a region of amino acids from 118 to 133 (QVDFEAINALKPDLII, showing the invariably conserved residues in bold) shows strong conservation to an amino acid sequence which has been identified as a signature sequence for periplasmic siderophore-binding proteins (Park \& Richardson, 1995; Tam \& Saier, 1993). It is likely, therefore, that CeuE is the periplasmic binding protein of the enterochelin transport system. CeuE has a signal sequence which conforms to the consensus sequence recognized by signal peptidase II (von Heijne, 1989; Pugsley, 1993). We have shown previously that the homologue of this protein from $C$. jejuni is expressed as a lipoprotein in E. coli (Park \& Richardson, 1995). To assess whether this protein was expressed as lipoprotein in $C$. coli, cells of the parental strain UA585 and $\mathrm{CCH} 1\left(\mathrm{CeuE}^{-}\right)$were grown in the presence of $\left[{ }^{3} \mathrm{H}\right]$ palmitate to effect the specific labelling of 
SD CeuB

ttattat tactaraaggaaaategctettaaacactggteagttaaatattctt. 60

$$
\begin{array}{lllllllllllllllllll}
L & L & F & K & H & L & F & S & L & N & I & L & L
\end{array}
$$

taattt tacttgttgttttrggaataataagct tatt cataggggt attcgtatcaatt 120

$$
\begin{array}{lllllllllllllllllllll}
I & L & I & V & V & F & G & I & I & S & I & F & I & G & V & I & R & I & N & L
\end{array}
$$

tagacgatattettcactcagcactacccagctcgaarcatttract acaagaattc 180

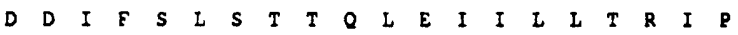

caagact at gcaatet tactt a caggt atgagt et tagt at atgcggact cat catge 240

$\begin{array}{lllllllllllllllllllll}R & I & I & A & I & L & L & T & G & M & S & I & S & I & C & G & L & I & M & Q\end{array}$

aacaactcacgcaaataaettgt $\div$ tct ccaaccactgcagggactatggattgtgcta 300

$\begin{array}{llllllllllllllllllll}Q & L & T & Q & N & K & F & V & S & P & T & T & A & G & T & M & D & C & A & K\end{array}$ aattggcatt tgatt ctetaatactttt acaggagettcettttract caagctc 360

$\begin{array}{llllllllllllllllllll} & G & I & L & I & S & L & I & F & F & T & G & A & S & F & F & T & Q & A & L\end{array}$ tcatcgcatctatttttget ctt teaggt tet tt tatatttat ccaaat ctaagaaaa 420

$\begin{array}{llllllllllllllllllll}I & A & S & I & E & A & L & L & G & S & F & I & E & I & Q & I & L & R & K & I\end{array}$ ttaaact aaagatgtgatttttgtgcetttgataggattaatgtttggtgggattataa 480

$\begin{array}{lllllllllllllllllllll}K & L & K & D & V & I & F & V & P & \text { L } & I & G & L & M & F & G & G & I & I & N\end{array}$ atgctataaccactttettgct tasgcttraaattatatacaaatat ccaaggctggc 540 $\begin{array}{lllllllllllllllllllll}A & I & T & T & F & F & A & Y & A & L & N & Y & I & Q & N & I & Q & G & W & L\end{array}$ tacagggcagtatggcaaatgttatgcagggaaattatgaattgctt tatattctttac 600

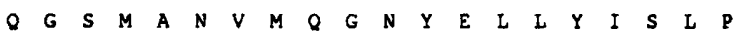
cgctettatact get $2 a t t t c t a g c c t a t a a a t c a c t a t$ agcaggtatgggagaag 660 $\begin{array}{llllllllllllllllllll}L & F & I & I & A & Y & F & I & A & Y & K & I & I & I & A & G & M & G & E & D\end{array}$

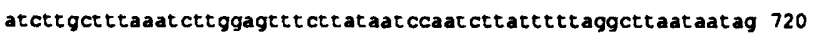
$\begin{array}{llllllllllllllllllll}\text { L } & A & L & N & L & G & V & S & Y & N & P & I & L & F & L & G & I & I & I & V\end{array}$ tttctattatcact agcgtagtgategtaagcattggagttatacctttetaggtctta 780

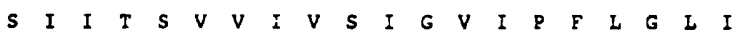
tcatccctaatcttgttgccatt a: cgcggggataatct ceagaaaatct at ctata 840 $\begin{array}{lllllllllllllllllllll}I & P & N & L & V & A & I & Y & R & G & D & N & L & K & K & N & I & I & Y & I\end{array}$ tagcattatgcggggcttgettttactattggegatattatctcaagact gtgattt 900

$\begin{array}{llllllllllllllllllll}A & L & C & G & A & I & F & L & L & I & C & D & I & I & S & R & L & V & I & F\end{array}$ ttcetttgaaatgcett tgagtataaccacaggtgttetgggetcttraattttatt 960 $\begin{array}{llllllllllllllllllll}P & F & E & M & P & L & S & I & T & T & G & V & L & G & S & L & I & F & I & F\end{array}$

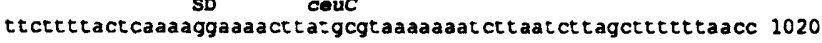

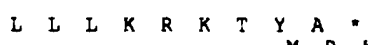
$M$ R K K I L I L A F I T cttat aat ggcact gettetgtat:tgcaggtt taaagatttgatgaatacgaatta 1080 $\begin{array}{llllllllllllllllllll}L & I & M & A & L & V & E & V & F & A & G & L & K & D & F & D & E & Y & E & L\end{array}$ aaaat cgctetergcaaat cgcaget attgttatagtggctatttgtatagctatatca 1140 $\begin{array}{llllllllllllllllllll}K & N & R & F & L & Q & \text { I } & \text { A } & \text { A } & \text { I } & \text { V } & \text { I } & V & \text { A } & \text { I } & \text { C } & \text { I } & \text { A } & \text { I } & S\end{array}$ act gtgatete caaact ct trgcaataacaaaat thtaaccecgccatcatagget 1200

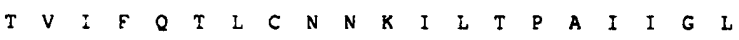

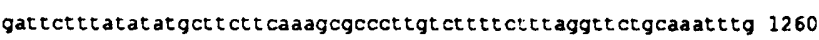
D $S \begin{array}{lllllllllllllllllll} & L & Y & M & L & L & Q & S & A & L & V & F & S & L & G & S & A & N & L\end{array}$ agtgtatatagaaatgatattaatetttaaccactcragcttgratggttgtatttet 1320 $\begin{array}{llllllllllllllllllll}S & V & Y & R & N & D & I & N & F & \text { i } & I & T & \text { i } & A & C & M & V & V & F & S\end{array}$ ttaggacttrataaatt ctttt tagcagtgataaaglatttatcttatcatgcttta 1380

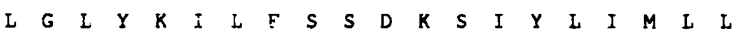
ggttgattttggaacactettagcacactaagctctettettgaaatctcatcgat 1440

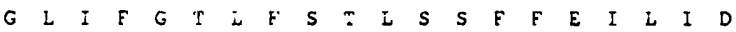
cctgatgaatcatgattat caaggaagaatgttrgcaagtttlgataatgtagcttt 1500

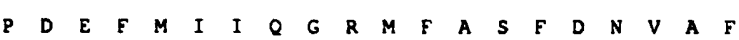
gatgetttagccet gettatat eg: aactegcttagt:ttatttggattettcgctat 1560

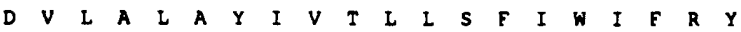
atgaaattettagaccett aagct gggcaaggatt tatccataaatttagggataaac 1620 $\begin{array}{llllllllllllllllllll}M & K & F & \text { L } & D & P & L & S & L & G & K & D & L & S & I & N & L & G & I & N\end{array}$ tatcaaaaattcaaaacatct atgataataattgctattttaactectattagcaca 1680

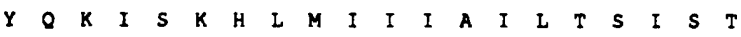
gcact $g$ grggt cet at cacct $t$ cce aggact $t$ t agt agt aaat at cact acgaact 1740 $\begin{array}{llllllllllllllllllll}A & L & V & G & P & I & T & F & \text { L } & G & L & L & V & V & N & I & T & Y & E & L\end{array}$ tttaaaactgcaaagcatagcattttactact tgcttgcatactcattagcattttagct 1800

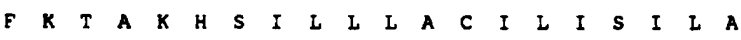
ttact gggggagtattttttgt ctctagaatecttgattacaatacaaccataagcgtt 1860 $\begin{array}{lllllllllllllllllllll}I & I & G & G & V & F & F & V & S & R & I & F & D & Y & N & T & T & I & S & \underset{c o u D}{V}\end{array}$ attatcaatttttaggtggaatatatttatctatcttgtattaaaggcaataacta 1920

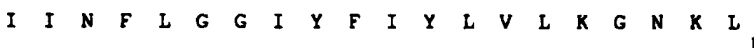
tgataagattacaaatatcaccaaat gctacgat caaaggctat catttcagatctta 1980

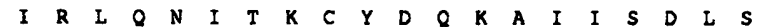
gtatcgatttecataaaggaaaattact ccattataggggcaatggagcagaaaat 2040

$\begin{array}{llllllllllllllllllll}I & D & F & H & K & G & K & \text { : } & T & S & I & I & G & A & N & G & A & E & K & S\end{array}$ ctactctttagct ctt gcaagt cgtttaat caaaccegat agtgggcgaat ct atat cg 2100

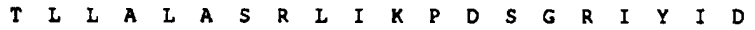
atggcatgaat tragcactatacaagaacaagatct tgcgcaaaaatt ccattctta 2160

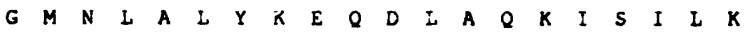
aacagcaaaat catattaatgtaagat taaaagt tgaagaattggt cgcatt ggacgct 2220

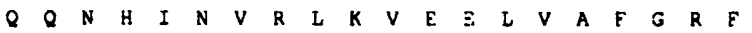
ttccacact ct caaggaagaattaattraacgataaaatgaaatcgatgaagcacttg 2280 $\begin{array}{llllllllllllllllllll}P & H & S & Q & G & R & I & N & L & N & D & K & M & K & I & D & E & A & L & E\end{array}$ aggatatgggact aacact $=t a a g a a a t a a t t t t a g a c a c g t$ taagtgggggacaaac 2340 $\begin{array}{lllllllllllllllllllll}D & M & G & L & N & T & I & R & N & N & F & R & H & V & K & W & G & T & K & Q\end{array}$ aaagagct $\tau t$ atacgaatcattat agct caagatactgaatt tat catgtttgatgaac 2400

$\begin{array}{llllllllllllllllllll}R & A & F & I & R & I & I & I & A & Q & D & T & E & F & I & M & F & D & E & P\end{array}$ ctcttaataat cttgatatgaaacatagcgtacaaat catgcaact tatgaaacgtttag 2460

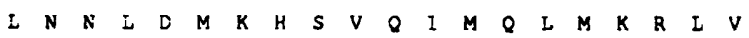
caaagacttraataaaagcatagccgtt gtacttcargatatcaattt tgct cgattt 2520

$\begin{array}{llllllllllllllllllll}K & D & F & N & K & S & I & A & V & V & \text { L } & H & D & I & N & F & A & S & I & y\end{array}$ attctgatgaaatcatagccctaaaaatggaaaact cttaaaacagggtt aaaagatg 2580

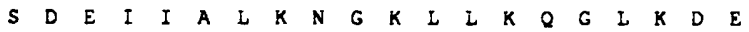
aaatcatccaagaagatgtettaagacaatttatgatatggatatccctgtaagtcaga 2640 $\begin{array}{lllllllllllllllllllllllll} & I & Q & E & D & V & L & R & Q & I & \searrow & D_{S D} & D & I & P & V & S & Q & I\end{array}$

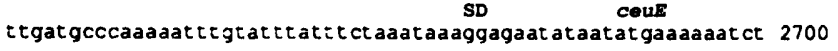

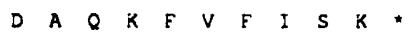
$M \quad K \quad S$ ttagttttgcattettegcatccttetaagtctaatttaacagcttgcgatcctaaa 2760

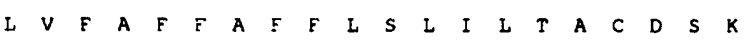
tccaargaaacaacgcaagt actgcaat aaaactagcactacggt aaaggt tatacct 2820

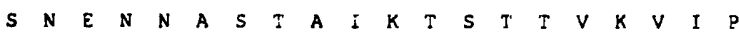
attagtatgagtgatgagggtgatagcttettagtaaaagatagcetaggtgaaaataaa 2880 I $S M S A$

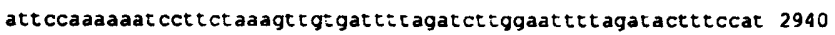

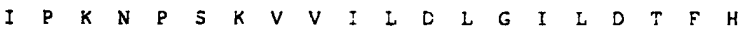

Fig. 2. For legend see facing page. 
gcectaagact taacgat aaagtt gcaggagt tecagctaaaaacttgccaaaatact ta 3000 $\begin{array}{llllllllllllllllllll}A & I & R & L & N & D & K & V & A & G & V & P & A & K & N & L & P & K & Y & L\end{array}$ cagcaatt aaagacaagcctagtataggtggagt tcaacaagttgattt gaagctatt 3060

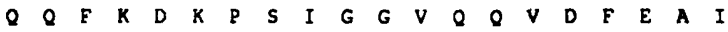
aat gct t aaaacct gat ct $t$ att at cattr ceggacgccaaagcaaatt tatgaaaa 3120 $\begin{array}{llllllllllllllllllll}N & A & L & K & P & D & L & I & I & I & S & G & R & Q & S & K & F & Y & E & K\end{array}$ ttgaaaat get ccaactatgtttgtaggact tgataatgcaaatt cttaagctetett 3180 $\begin{array}{llllllllllllllllllll}L & K & I & A & P & T & M & F & V & G & L & D & N & A & N & F & L & S & S & F\end{array}$ gaaacaatgt $t$ t taagcgt tgcaaaact $t$ atgget $t$ agaaaagaagct t ctgaaaaa 3240 E N N V L S $\quad$ S A $A$ K attgcagatat taaaatgagatagaacaagcaaaagcatagtagatgaagataazaaa 3300 $\begin{array}{llllllllllllllllllll}I & A & D & I & K & N & E & I & E & Q & A & K & S & I & V & D & E & D & K & K\end{array}$ gctet tattgt tctaaccaat $t$ ctaacaaatet ccgctttggacctcaat ctcgct $t$ 3360 $\begin{array}{llllllllllllllllllll}A & L & I & V & L & T & N & S & N & K & I & S & A & F & G & P & Q & S & R & F\end{array}$ ggaat cat $t$ cat gat gt $t$ t $t$ aggaat caatgct gt ggatgaaatgt aaagt aggcaca 3420

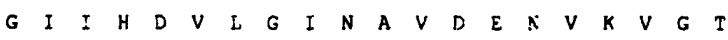
catggaaaagcattaattctgaat $c$ tatactagaaaaaatcctgattatctatttgta 3480 $\begin{array}{llllllllllllllllllll}H & G & K & S & I & N & S & E & F & I & L & E & K & N & P & D & Y & L & F & V\end{array}$ gttgatagaatatcattgtgggcaataaagacgcgcacaaggcatactgataatgca 3540 $\begin{array}{llllllllllllllllllll}V & D & R & N & I & I & V & G & N & K & E & R & A & Q & G & I & L & D & N & A\end{array}$ cttgtaactaaaaccaacgetgctacaaataataaarcattlatcttgatcctgaatac 3600 $\begin{array}{llllllllllllllllllll}I & V & T & K & T & N & A & A & T & N & N & K & I & I & Y & I & D & P & E & Y\end{array}$ tggtat ctagcaagt ggcaatggct tagaat cat $t$ aaaaccatgattt agaagtaaca 3660

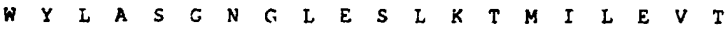
aacgctattaaataaaccctatghaagagaagt tgt tctct acaftctatfatccaaat 3720 N A $\mathbf{L}$ K

ccaactat caagtacaaatct taaazaaatt tagit:atatccact ataaaaattcac 3780 tttcget tcacat ctettgrcaaat accatacaaat tgataatcaaaaggagagaaa 3840 Orfa

atgat taacaaaacaaat tatt

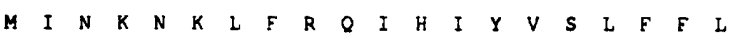
ccetgtgctgtactettgcact acagggattgcttatatcettggagccgatcaagat 3960 P C C A $\quad$ V acgggttraaaggtagaaact tarajact tgtaaaaaatatagaacct.ggtaaagaaaa 4020

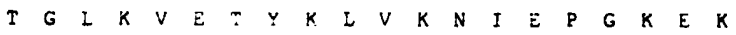
gatgcactcatccaatactcacaagaaaacaatttaaaagttccatctgacgctgaagct 4080

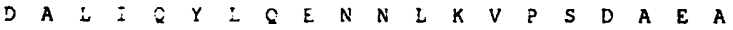
act caaggcaaaggcaagggggcgaatargggcggaatacaccataatgcgaatgcagct 4140 $\begin{array}{llllllllllllllllllll}T & Q & G & K & G & K & G & A & N & M & G & G & I & H & H & N & A & N & A & A\end{array}$ cccgctaatgt caaagctggcaaaggtaaaacaatgaataactataggtggagcacat 4200 $\begin{array}{llllllllllllllllllll}P & A & N & V & K & A & G & K & G & K & N & N & E & I & T & I & G & G & A & H\end{array}$ tat agcgccaat at aact cetgrtg:tcaaargagt atataat aact ct taaaactaga 4260

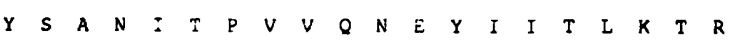
tett gttaggcgat atgat catcc:tcataaagataaaggggcgtggtattettctgtg 4320 S I L L $G \begin{array}{lllllllllllllllll} & \text { G } & M & \text { I } & M & \text { L } & H & K & D & K & G & A & W & Y & F & S & V\end{array}$ cttagcataggett tggtattgettiattettactctatatct caggact atcattact 4380

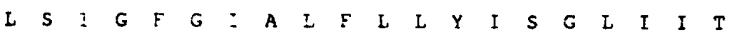
tta:ttgctagcaaaaaagatagacaaaaacagct tgcaacacttggagctggggttgtt 4440

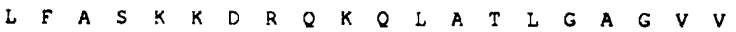
atcactatactettagctiatctiagtecttaatecttatetagctetetaagctag $\mathbf{4 5 0 0}$
I $I$ I L I A $\quad Y$ \& $S$ L *

gtattatctaatttttatataat cacactt aatetattggacagatgggtgagcgget 4560 gaaaccacaccct get aagggtgcagat ct taat cgggtct cgagggt t caaat ccctc 4620 tctgrcegccactgact $t c a a a a a a a c t a t c a a c t a t c a t t t$ aattacct tt tatat 4680

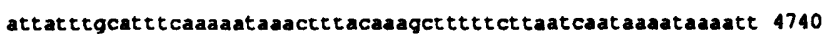
caatt thatcetcatttetcaaccaaataacgcaagctt aaaaraaaattectatac $\mathbf{4 8 0 0}$ tttatccatctaaataaatgagctettt cgtataatccaacaataaattgottattt $\mathbf{4 8 6 0}$ ttcatttaaaaacgatctatttaaagcaaagaagcattgatttaaatcctaatttaaaa 4920 aactataaaattattctgtcgtttctcttaagcaagtgctatattettataaatccat 4980 cttat cgtgtgtactaaacaactcaaartaatcatagacattttatctataaaattta 5040 ctgct taaagcaragaaaatataaaacartaaacagataaaattataagattttatt 5100

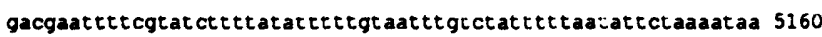
ttgaaagat at aaaaaagccet aaat at agggcttt taagaa

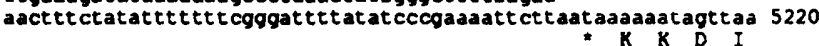
tgaact attaatatgcct cgt tccaaaaragcacaagatt tcaagaaacctcctaat 5280 V $Q$ Y N Y P A L N K D H E L L E K ? P N $\underset{G}{g}$ traatgaagataaagt agt ggt at tat tgcgagaggacgauatacaggt caat tgtag 5340

aatcgcaat at tattcgagagg cct aatctaaaadcgratagaagtttggattraaa $\mathbf{5 4 0 0}$ K A N Y Y L E G P N F K Q M D E F G L N cttcaaattt tagt aat tacggtaatcgt aat cgttaaagatattcaaattaaacagga 5460 cttcaaaatt tagt aat acggtaat cgt aat cgttaaagatatt caaatt aaacagga caaaatcggtatagatgt cgaacatct tcgtaagaact cggagtgctcctaacacctt 5520 I K A M D V A O L L M R S A E R P N H F ggacaact aaaagt agt aat ggttet agt cgagagtaaact ct aaacgccact cgaga 5580 $\underset{G}{G} \mathbf{S}$ N E A N V E D A R M O S K R H L E

Fig. 2. Nucleotide sequence of the $C$. coli ceuB, ceuC, ceuD and ceuE genes and the deduced amino acid sequences. The putative Shine-Dalgarno sequences are denoted by SD. An inverted repeat representing a potential rho-independent terminator is underlined. 


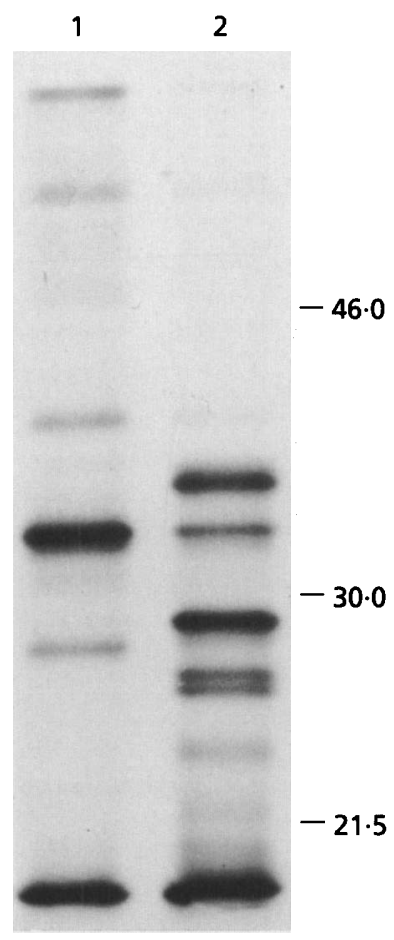

Fig. 3. Analysis of proteins expressed from the plasmid pS1. A fluorograph of $\left.{ }^{35} \mathrm{~S}\right] \mathrm{methionine-labelled} \mathrm{proteins} \mathrm{expressed} \mathrm{in}$ an in vitro coupled transcription/translation system using the parental plasmid pSP105 (lane 1) and pS1 (lane 2) as templates is shown. The positions of standard proteins are given in $\mathrm{kDa}$.

lipoproteins. The expression of components of siderophore-uptake systems is often repressed during growth in iron-replete conditions. The expression of lipoproteins was therefore assessed in cells with respect to the availability of iron. When lipoprotein expression in cells of the parental strain was examined in this manner, a $34 \mathrm{kDa}$ lipoprotein, expressed only when the availability of iron was restricted by the addition of $20 \mu \mathrm{M}$ EDDHA, was apparent (Fig. 5). In contrast, this iron-repressible protein was not apparent in lysates of $\mathrm{CCH} 1$ cells which had been grown under iron-deficient conditions. Instead a faint band which represented a protein of $31 \mathrm{kDa}$ was seen. These observations suggest that the iron-repressible

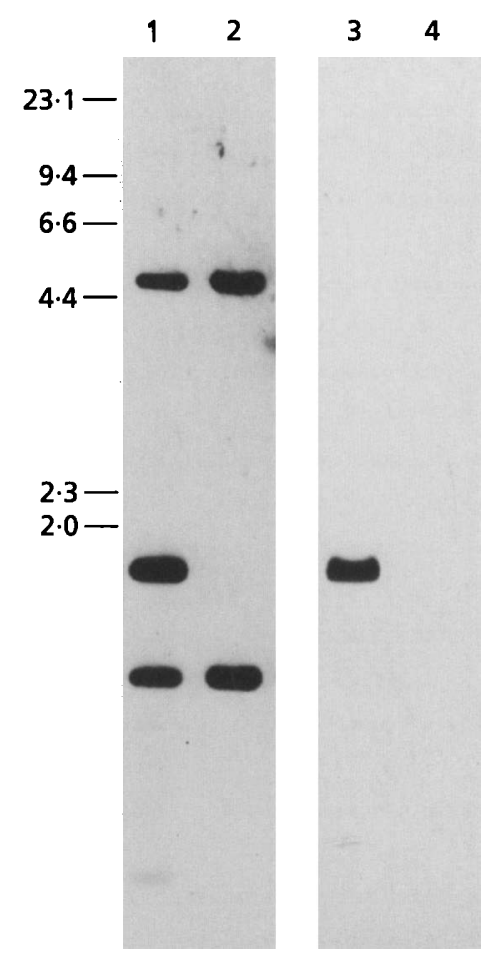

Fig. 4. Confirmation of the deletion in $C$. coli CFED 1 by Southern analysis. Genomic DNA from $C$. coli UA585 (lanes 1 and 3 ) and C. coli CFED1 (lanes 2 and 4) was digested with Bg/ll and probed with the $2.1 \mathrm{~kb}$ insert in PCFF1 (lanes 1 and 2) or with the $1.3 \mathrm{~kb} \mathrm{Bg} / \mathrm{ll}$ fragment removed during the construction of pCFED1 (lanes 3 and 4). The size of molecular size standards is shown in $\mathrm{kb}$.

$34 \mathrm{kDa}$ lipoprotein represents CeuE since it is absent from the ceuE mutant CCH1. The appearance of a $31 \mathrm{kDa}$ protein in $\mathrm{CCH} 1$ cells is consistent with this as the integrative event, which led to the mutation in $\mathrm{CCH} 1$, would have generated a truncated $c e u E$ gene which could potentially encode a mature protein of $30 \cdot 6 \mathrm{kDa}$.

\section{ceuB and ceuC encode the putative enterochelin- specific permease}

The deduced amino sequences of CeuB and CeuC reveal that these proteins are very hydrophobic and contain a

Table 2. Haemin and enterochelin utilization by C. coli

Growth response to iron compounds on $\mathrm{MH}$-plates containing $56 \mu \mathrm{M}$ EDDHA was classified as: +++ , very good growth; ++ , good growth; + , weak growth; \pm , very weak growth; - , no growth.

\begin{tabular}{|c|c|c|c|c|}
\hline \multirow[t]{2}{*}{ Strain (genotype) } & \multicolumn{2}{|c|}{ Growth with enterochelin } & \multicolumn{2}{|c|}{ Growth with haemin } \\
\hline & $1 \mathrm{mM}$ & $100 \mu \mathrm{M}$ & $1 \mathrm{mM}$ & $100 \mu \mathrm{M}$ \\
\hline UA585 & +++ & ++ & ++ & ++ \\
\hline $\mathrm{CCH} 1(c e u E)$ & ++ & \pm & ++ & ++ \\
\hline CATP1 $(c e u D)$ & + & - & ++ & ++ \\
\hline CFED1 $(\Delta$ ceuB-ceuD $)$ & + & - & ++ & ++ \\
\hline
\end{tabular}




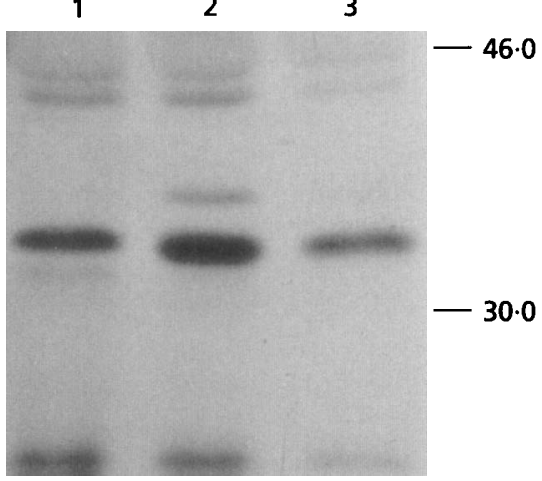

Fig. 5. Lipophilic modification of CeuE. Cells of C. coli UA585 grown in iron-replete broth (lane 3) or broth containing $20 \mu \mathrm{M}$ EDDHA (lane 2), and cells of $\mathrm{C}$. coli $\mathrm{CCH} 1$ grown in broth containing $20 \mu \mathrm{M}$ EDDHA (lane 1), were incubated in the presence of $\left[{ }^{3} \mathrm{H}\right]$ palmitate and the labelled proteins were analysed by SDS-PAGE and fluorography. The positions of standard proteins are given in $\mathrm{KDa}$.

number of potential membrane-spanning segments. These characteristics are consistent with the hypothesis that $\mathrm{CeuB}$ and $\mathrm{CeuC}$ are integral membrane protein components of the PBT system. There is often significant homology between the inner-membrane permeases of PBT systems (Staudenmaier et al., 1989). A pair-wise comparison of the amino acid sequences of CeuB and CeuC revealed that $26.3 \%$ of their amino acids were identical. Furthermore, both sequences showed significant homology to the group of proteins that are the subunits of the cytoplasmic membrane permeases for the transport of ferric siderophores. CeuB showed $40.9 \%$ homology (identical amino acids) to FatD (Vibrio anguillarum anguibactin transport; Koster et al., 1991) and $26.7 \%$ homology to FepD (E. coli enterochelin transport; Shea \& McIntosh, 1991). Similarly, CeuC displayed $31.6 \%$ homology to FatC ( $V$. anguillarum anguibactin transport; Koster et al., 1991) and $22 \%$ to HemU (Yersinia enterocolitica haemin uptake; Stojiljkovic \& Hantke, 1994). Specifically, the conserved regions for the integral membrane proteins identified by Staudenmaier et al. (1989) are partially conserved in CeuB and CeuC. The tetrapeptide in the first conserved region RLPR is represented by RIPR in CeuB but is not apparent in CeuC. The highly conserved FIGL in region five (Staudenmaier et al., 1989) is present as FLGL in both CeuB and CeuC. The homology box in the third region of conservation starting with $Q$ and containing NP preceded by a charged amino acid was represented by QQLTQNK and QTLCNNK in CeuB and CeuC, respectively.

\section{ceuD encodes the putative ATP-binding component of the enterochelin uptake system}

The ceuD gene encodes a protein with significant homology to the ATP-binding proteins from other PBT systems for ferric siderophores. It shows $36.5 \%$ homology (identical amino acids) with FhuC (E. coli hydroxymate uptake; Burkhardt \& Braun, 1987), 32.9\% homology with $\mathrm{FecE}$ (E. coli ferric-citrate uptake; Staudenmaier et al., 1989) and 32.6\% homology with FepC (E. coli enterochelin uptake; Shea \& McIntosh, 1991). In support of the concept that CeuD is the ATPbinding protein for the enterochelin transport system, it also contains the sequence GANGAGKST, which compares well with $G \times x G x G K S / T$ which is the consensus sequence motif associated with the glycine-rich loop of ATP-binding proteins (Walker et al., 1982). In addition, it contains a second conserved region, containing the invariant residue DEP, which is typical of ATP-binding proteins (Walker et al., 1982).

\section{DISCUSSION}

In a variety of bacterial pathogens iron availability and the sequestration of this essential element are intimately associated with virulence (Payne \& Lawlor, 1990; Wooldridge \& Williams, 1993). A description of the factors which enable Campylobacter to become established within the host and cause disease would, therefore, be incomplete without an understanding of the mechanisms through which this group of pathogens are able to acquire iron. Prior to this study information concerning the biochemistry and genetics of siderophore uptake in Campylobacter species was lacking. As a first step towards a molecular description of iron uptake in this pathogen we have used a genetic approach to characterize a PBT system for the uptake of the catechol type siderophore enterochelin.

Previously, a lipoprotein, isolated from $C$. jejuni NCTC 11351 and with significant homology to siderophorebinding proteins, was characterized in our laboratory (Park \& Richardson, 1995). The function of this protein could not, however, be confirmed by the generation of isogenic mutants because this strain has proven refractory to the introduction of recombinant DNA (K. A. Grant \& S. F. Park, unpublished data). In this study we have identified the homologue in $C$. coli UA585, which is naturally competent and amenable to genetic manipulation (Wang \& Taylor, 1990). Plasmid rescue was used to clone the DNA sequences flanking the gene encoding this protein from this strain. Analysis of this region identified four ORFs encoding proteins with significant homology to the components of PBT systems for the transport of ferric siderophores. Mutational analysis showed that these components were essential for the efficient uptake of the siderophore enterochelin. Genes which encode other bacterial PBT systems are often transcribed as operons (Staudenmaier et al., 1989). Given that the ceuBCDE genes are all orientated in the same direction and that only relatively small intergenic distances separate the reading frames or the genes overlap, it is likely that the $c e u B C D E$ genes are transcribed as part of an operon. It is also probable that $c e u E$ is the last gene in the ceu operon for two reasons. Firstly, the deduced protein product of ORFA bears no homology to any known protein associated with iron acquisition and secondly, the intergenic region between $c e u E$ and ORFA is much larger than that for any of the other ceu genes and it contains a potential rhoindependent transcriptional terminator. It is highly likely, 
therefore, that the phenotypic effects observed in the various $c e n$ mutants are a result of the disfunction of components of the putative PBT system and are not caused by polar effects.

All known bacterial PBT systems consist of at least three components: a periplasmic binding protein, one or two integral membrane components and one or two ATPbinding proteins (Ames et al., 1990). According to its deduced amino acid sequence and phenotypic characterization, it is likely that CeuE is the periplasmic enterochelin-binding protein. Mutants in $c e u E$, defective in the putative enterochelin-binding component, were still able to utilize enterochelin, although the stimulation of growth due to the siderophore was significantly reduced compared to the wild-type. Ferric siderophores are needed in very small amounts so it is possible that they can be accumulated to a sufficient concentration to allow a degree of growth even if part of the transport system has been disabled. Our data also indicate that CeuE is a lipoprotein since an iron-repressible $\left[{ }^{3} \mathrm{H}\right]$ palmitatelabelled $34 \mathrm{kDa}$ protein, corresponding to the predicted size of the processed CeuE protein, was absent in cells containing a $c e u E$ mutation. The presence of a lipophilically modified substrate-binding protein is unusual in a Gram-negative organism. In Gram-positive organisms, however, this is a common adaptation (Alloing et al., 1990; Schneider \& Hantke, 1993), and in the absence of an outer membrane the lipid moiety is thought to interact with the cytoplasmic membrane to form an anchor to prevent the escape of the protein (Gilson et al., 1988). The reason for the presence of a substrate-binding lipoprotein in $C$. coli is at present unclear. Recently, however, a protein, identified as a cell-binding factor of $C$. jejuni, has been shown to be homologous to the binding proteins of amino acid transport systems in Gram-negative bacteria (Pei \& Blaser, 1993). This protein is predicted to have both signal peptidase I and signal peptidase II cleavage sites and it has been suggested that this characteristic allows the protein to occupy different locations so that it can perform multiple functions. The two-step cleavage of the leader peptide of the protein may distinguish it from amino acid binding proteins and make it accessible to the bacterial surface where it can perform cell binding functions as well (Pei \& Blaser, 1993). We have shown that CeuE, which contains a signal peptidase II site and is lipophilically modified, is likely to function as a siderophore-binding protein in a PBT system for enterochelin uptake. Whether it undergoes the two-step processing suggested by Pei \& Blaser (1993), enabling it to perform another function on the cell surface, is not known but it is interesting to note that $c e u E$ contains a weak signal peptidase I recognition site $\left({ }^{31} \mathrm{~S}-\mathrm{X}^{-33} \mathrm{~A}\right.$; Fig. 2).

The amino acid sequence similarities between CeuB, $\mathrm{CeuC}$ and CeuD and components of cytoplasmic membrane permease complexes of siderophore-bindingprotein-dependent transport systems from other bacteria is striking given the phylogenetic distances between campylobacters and the other species. Generally these assemblies comprise one or two hydrophobic trans- membrane components and one or two hydrophilic components with ATP-binding domains (Ames et al., 1990). In view of the structural characteristics predicted from their amino acid sequences it is likely that CeuB and $\mathrm{CeuC}$ form the integral membrane components and that CeuD is the ATP-binding protein. When the genes encoding this complex were disrupted, enterochelin utilization was severely impaired. The mutants showed no growth response when enterochelin was supplied at $100 \mu \mathrm{M}$, but at higher concentrations of the siderophore both the ceuD insertion mutant and the $c e u B C D$ deletion mutant exhibited a very weak zone of growth stimulation. A similar phenomenon has been observed for haemin PBT-system-deficient mutants of $Y$. enterocolitica (Stojiljkovic \& Hantke, 1994). In this situation it has been proposed that the formation of a haemin gradient between the periplasm and cytoplasm may facilitate the leakage of this hydrophobic compound through the cytoplasmic membrane into the cell. It is possible, therefore, that the same mechanism could account for the weak growth stimulation, due to enterochelin, that was observed in the permease-defective mutants of $C$. coli.

In conclusion, we have identified and characterized a PBT system for the uptake of enterochelin in $C$. coli. Although this bacterium does not appear to produce enterochelin or any other known siderophore (S. F. Park, unpublished data; Baig et al., 1986; Field et al., 1986) it seems likely that this pathogen can utilize this transport system to scavenge the enterochelin produced in the gastrointestinal tract by E. coli and other enteric bacteria. The transport-defective mutants generated in this study will allow the role of the enterochelin-uptake system in promoting the virulence of C. coli to be assessed.

\section{ACKNOWLEDGEMENTS}

We thank K. Hantke (University of Tubingen) and J. B. Neilands (University of California) for generously providing siderophores. We are also grateful to D. E. Taylor (University of Alberta) for the gift of C. coli UA585.

\section{REFERENCES}

Alloing, G., Trombe, M. C. \& Claverys, J. P. (1990). The ami locus of Streptococcus pneumoniae is similar to binding-protein dependent transport operons of Gram-negative bacteria. Mol Microbiol 4, 633-644.

Ames, G. F.-L., Mimura, C. S. \& Shyamala, V. (1990). Bacterial periplasmic permeases belong to a family of transport proteins operating from Escherichia coli to human: traffic ATPases. FEMS Microbiol Rev 75, 429-446.

Baig, B. H., Wachsmuth, I. K. \& Morris, G. K. (1986). Utilization of exogenous siderophores by Campylobacter species. J Clin Microbiol 23, 431-433.

Braun, V. \& Hantke, K. (1991). Genetics of bacterial iron transport. In Handbook of Microbial Iron Chelates, pp. 107-138. Edited by G. Winkelmann. Boca Raton, FL: CRC Press.

Briat, J.-F. (1992). Iron assimilation and storage in prokaryotes. $J$ Gen Microbiol 138, 2475-2483.

Burkhardt, R. \& Braun, V. (1987). Nucleotide sequence of the $f b u C$ and $f b u D$ genes involved in iron(III)hydroxymate transport: 
domains in FhuC homologous to ATP-binding proteins. Mol \& Gen Genet 209, 49-55.

Crosa, J. H. (1989). Genetics and molecular biology of siderophoremediated iron transport in bacteria. Microbiol Rev 53, 517-530.

Devereux, J., Haeberli, P. \& Smithies, O. (1984). A comprehensive set of sequence analysis programs for the VAX. Nucleic Acids Res 12, 387-395.

Dickinson, J. H., Grant, K. A. \& Park, S. F. (1995). Targeted and random mutagenesis of the Campylobacter coli chromosome using integrational plasmid vectors. Curr Microbiol 31, 1-5.

Field, L. H., Headley, V. L., Payne, S. M. \& Berry, L. J. (1986). Influence of iron on growth, morphology, outer membrane protein composition, and synthesis of siderophores in Campylobacter jejuni. Infect Immun 54, 126-132.

Gilson, E., Alloing, G., Schmidt, T., Claverys, J. P., Dudler, R. \& Hofnung, M. (1988). Evidence for high affinity binding-proteindependent transport systems in Gram-positive bacteria and in mycoplasma. EMBO J 7, 3971-3974.

Griffiths, P. L. \& Park, R. W. A. (1990). Campylobacters associated with human diarrhoeal disease. J Appl Bacteriol 69, 281-301.

von Heijne, G. (1989). The structure of signal peptides from bacterial lipoproteins. Protein Eng 2, 531-534.

Higgins, C. F. (1992). ABC transporters: from microorganisms to man. Annu Rev Cell Biol 8, 67-113.

Koster, W. L., Actis, L. A., Waldbeser, L. S., Tolmasky, M. E. \& Crosa, J. H. (1991). Molecular characterization of the iron transport system mediated by the pJM1 plasmid in Vibrio anguillarum 775. $J$ Biol Chem 266, 23829-23833.

Labigne-Roussel, A., Courcoux, P. \& Tompkins, L. (1988). Gene disruption as a feasible approach for mutagenesis of Campylobacter jejuni. J Bacteriol 170, 1704-1708.

Laemmli, U. K. (1970). Cleavage of structural proteins during the assembly of the head of bacteriophage T4. Nature 227, 680-685.

Maniatis, T., Fritsch, E. F. \& Sambrook, J. (1982). Molecular Cloning: a Laboratory Manual. Cold Spring Harbor, NY: Cold Spring Harbor Laboratory.

Mead, D. A., Szcesna-Skoripa, E. \& Kemper, B. (1986). Singlestranded 'blue' $T 7$ promotor plasmids : a versatile tandem promoter system for cloning and protein engineering. Protein Eng 1, 67-74.

Neilands, J. B. (1981). Microbial iron compounds. Annu Rev Biochem 50, 715-731.

Park, S. F. \& Richardson, P. T. (1995). Molecular characterization of a Campylobacter jejuni lipoprotein with homology to periplasmicsiderophore-binding proteins. J Bacteriol 177, 2259-2264.

Payne, S. M. \& Lawlor, K. M. (1990). Molecular studies on iron acquisition by non-Escherichia coli species. In The Molecular Basis of Bacterial Pathogenesis, pp. 225-248. Edited by B. H. Iglewski \& V. L. Clark. San Diego: Academic Press.

Pei, Z. \& Blaser, M. J. (1993). PEB1, the major cell-binding factor of Campylobacter jejuni, is a homolog of the binding component in Gram-negative nutrient transport systems. J Biol Chem 268, 18717-18725.

Pickett, C. L., Auffenberg, T., Pesci, E. C., Sheen, V. L. \& Jusuf, S. S. D. (1992). Iron acquisition and haemolysin production by Campylobacter jejuni. Infect Immun 60, 3872-3877.
Pitcher, D. G., Saunders, N. A. \& Owen, R. J. (1989). Rapid extraction of bacterial genomic DNA with guanidinium thiocyanate. Lett Appl Microbiol 8, 151-156.

Pugsley, A. P. (1993). The complete general secretory pathway in gram-negative bacteria. Microbiol Rev 57, 50-108.

Rogers, H. J. (1973). Iron-binding catechols and virulence in Escherichia coli. Infect Immun 7, 445-456.

Sanger, F., Nicklen, S. \& Coulson, A. R. (1977). DNA sequencing with chain-terminating inhibitors. Proc Natl Acad Sci US A 74, 5463-5467.

Schneider, R. \& Hantke, K. (1993). Iron-hydroxamate uptake systems in Bacillus subtilis: identification of a lipoprotein as part of a binding-protein-dependent transport system. Mol Microbiol 8, 111-121.

Shea, C. M. \& Mclntosh, M. A. (1991). Nucleotide sequence and genetic organization of the ferric enterobactin transport system: homology to other periplasmic-binding-protein-dependent systems in Escherichia coli. Mol Microbiol 5, 1415-1428.

Staudenmaier, H., Van Hove, B., Yaraghi, Z. \& Braun, V. (1989). Nucleotide sequences of the $f e c B C D E$ genes and locations of the proteins suggest a periplasmic-binding-protein-dependent transport system for iron (iii) dicitrate in Escherichia coli. J Bacteriol 171, 2626-2633.

Stojiljkovic, I. \& Hantke, K. (1994). Transport of haemin across the cytoplasmic membrane through a haemin-specific periplasmic binding-protein-dependent transport system in Yersinia enterocolitica. Mol Microbiol 13, 719-732.

Tam, R. \& Saier, M. H., Jr (1993). Structural, functional, and evolutionary relationships among extracellular solute-binding receptors of bacteria. Microbiol Rev 57, 320-346.

Tauxe, R. V. (1992). Epidemiology of Campylobacter jejuni in the United States and other industrialised nations. In Campylobacter jejuni: Current Status and Future Trends, pp. 9-19. Edited by I. Nachamkin, M. J. Blaser \& L. S. Tompkins. Washington, DC: American Society for Microbiology.

Walker, J. E., Saraste, M., Runswick, M. J. \& Gay, N. J. (1982). Distantly related sequences in the $\alpha$ and $\beta$-subunits of ATP synthase, myosin, kinase and other ATP-requiring enzymes and a common nucleotide binding fold. EMBO J 1, 941-945.

Walker, R. I., Caldwell, M. B., Lee, E. C., Guerry, P., Trust, T. J. \& Ruiz-Palacios, G. M. (1986). Pathophysiology of Campylobacter species. J Bacteriol 172, 949-955.

Wang, Y. \& Taylor, D.E. (1990). Natural transformation in Campylobacter species. J Bacteriol 172, 949-955.

Weinberg, E. D. (1984). The development of awareness of iron withholding defense. Perspect Biol Med 36, 215-221.

Wooldridge, K. G. \& Williams, P. H. (1993). Iron uptake mechanisms of pathogenic bacteria. FEMS Microbiol Rev 12, 325-348.

Yanisch-Perron, E., Vieira, J. \& Messing, J. (1985). Improved M13 cloning vectors and host strains: nucleotide sequences of the M13mp18 and pUC vectors. Gene 33, 103-119.

Received 7 June 1995; accepted 10 August 1995. 